\title{
Optimal Design of Commercial Vehicle Systems Using Analytical Target Cascading
}

\author{
Namwoo Kang ${ }^{1}$, Panos Y. Papalambros ${ }^{2}$ \\ University of Michigan, Ann Arbor, MI 48109, USA \\ Michael Kokkolaras ${ }^{3}$ \\ McGill University, Montreal, QC H3A OC3, Canada \\ Seungwon Yoo ${ }^{4}$, Wookjin $\mathrm{Na}^{5}$, Jongchan Park ${ }^{6}$ \\ Hyundai Motor Company, Hwaseong-Si, Gyeonggi-Do 445-706, Korea \\ Dieter Featherman $^{7}$ \\ Altair Engineering, Troy, MI 48083, USA
}

\begin{abstract}
This paper presents an industrial application of the analytical target cascading (ATC) methodology for the optimal design of commercial vehicle systems. It is the first milestone of a recently initiated research effort between Altair, Hyundai and the University of Michigan, whose objective is to develop and introduce a computational ATC tool platform into Hyundai's product development process so that the latter can be enhanced and streamlined. Two pilot studies are considered: the suspension design of a heavy-duty truck and the body structure design of a bus. An implementation novelty is the use of OptiStruct models for integrated analysis and optimization of the subproblems. The ATC results provide useful insight on the feasibility of system-level design targets and the adequacy of the subproblem design spaces.
\end{abstract}

\section{Nomenclature}

$\begin{array}{ll}R F & =\text { axle load } \\ K & =\text { stiffness } \\ D_{h} & =\text { gab between chassis and helper spring } \\ C B & =\text { relative free camber } \\ A, B, C, D, L_{3}, L_{6}=\text { dimensions of leaf spring } \\ m & =\text { mass } \\ f & =\text { frequency } \\ a & =\text { proportional factor of material property } \\ d_{i} & =\text { displacement for i-th assembly } \\ I_{1} & =\text { moment of inertia in plane } 1 \\ I_{2} & =\text { moment of inertia in plane } 2 \\ A & =\text { area of cross section } \\ w, h, t & =\text { dimensions of cross section }\end{array}$

\footnotetext{
${ }^{1}$ Ph.D. student, Design Science

${ }^{2}$ Professor, Department of Mechanical Engineering, AIAA Member

${ }^{3}$ Associate Professor, Department of Mechanical Engineering, AIAA Senior Member; work conducted while author was Associate Research Scientist at the Department of Mechanical Engineering at the University of Michigan

${ }^{4}$ Senior Research Engineer, Commercial Vehicle CAE Research Lab

${ }^{5}$ Senior Research Engineer, Commercial Vehicle CAE Research Lab

${ }^{6}$ Research Fellow, Commercial Vehicle CAE Research Lab

${ }^{7}$ Program Manager, Altair Product Design
}

American Institute of Aeronautics and Astronautics 


\section{Introduction}

$\mathrm{D}$ esign optimization of complex engineering systems can often be accomplished only by decomposition. The system is partitioned into subsystems, the subsystems are partitioned into components, the components into parts, and so on. The outcome of the decomposition process is a multilevel hierarchy of system-constituent elements. Hierarchical decomposition facilitates employing decentralized optimization approaches that aid systems engineers to identify interactions among elements at lower levels and to transfer this information to higher levels, and has in fact become standard design practice, as evidenced by the organizational structure of engineering companies.

Hyundai Motor Company (HMC) recognizes the importance of the decomposition approach, as its Research and Development (R\&D) center features a segmentalized organization due to the complexity of vehicle engineering systems. HMC intends to build a hierarchical and computational platform for commercial vehicle design to account for subsystem interactions and to investigate the relation between system design targets and subsystem responses; the objective is to be able to determine appropriate targets for current and new product designs for optimized vehicle-level performance. This can be a significant task at the early stages of new vehicle design because system engineers tend to rely on previous model specifications without thoroughly considering new design targets due to lack of information of system and subsystem interactions. HMC anticipates that the target values obtained from the hierarchical and computational design platform can serve as a guideline for engineering designers at the detail design phase.

Analytical target cascading (ATC) ${ }^{1}$ has been shown to be an effective model-based, hierarchical optimization methodology for identifying and accounting for subsystem interactions and translating system-level design targets to subsystem specifications while achieving system-level consistency and optimality. ATC has been applied successfully to several design problems in automotive, aerospace, manufacturing and civil engineering applications, but we focus here on automotive engineering applications ${ }^{2-5}$. The ATC methodology has theoretical convergence properties under standard assumptions ${ }^{6}$; moreover, recent formulation improvements and extensions have enhanced its computational behavior and applicability to a large class of multi-disciplinary design optimization (MDO) problems $^{7-8}$.

The scope of this paper is to demonstrate the successful implentation of the ATC process for two HMC vehicle systems. The first application considers the suspension design of a heavy-duty truck. The objective of this study was to investigate whether ATC would yield reasonable results relative to the existing HMC design target values. The second application considers the body structure design of a small bus. The goal of the second application is to design a new segmented middle-sized bus that is not included in HMC's current product line. For these two design problems, the University of Michigan has taken the lead in developing and implementing the appropriate ATC formulations for the vehicle systems, while Altair Engineering and HMC were responsible for providing simulation models.

The article is organized as follows. The ATC algorithm used in this study is presented briefly in Section II. The analysis models, ATC formulations and obtained results for the two applications are described in Sections III and IV, respectively. Conclusions are then drawn in Section V.

\section{Analytical Target Cascading}

Given a system decomposition that is usually object-based, ATC operates by exploiting the hierarchical functional dependencies that exist among subsystems, components, parts, etc. For each element at each level of the decomposition hierarchy, a design optimization problem is formulated and solved to i) satisfy targets set by elements at a level above and ii) dictate targets for the elements at the level below. Analysis or simulation models are used to compute element responses given element designs. In this manner, top-level system design targets are propagated down to lower subsystem- and component-level design specifications. The resulting responses are then rebalanced at higher levels by iteratively adjusting designs (and thus targets) to achieve system consistency.

The information flows to and from a subproblem $P_{i j}$ corresponding to the $j$-th element at the $i$-th level are illustrated in Fig. 1. The general subproblem $P_{i j}$ of Fig. 1 is given by Eq. (1). In this study, we use the augmented Lagrangian formulation for penalty function reported in Ref. 7. In the penalty function, $\mathbf{v}$ is the vector of Lagrangian multiplier parameters, $\mathbf{w}$ is a vector of penalty weights, and the 0 symbol is used to denote a term-by-term multiplication of vectors. $\mathrm{c}_{i j}$ is the number of children of element $j$ at level $i$. 


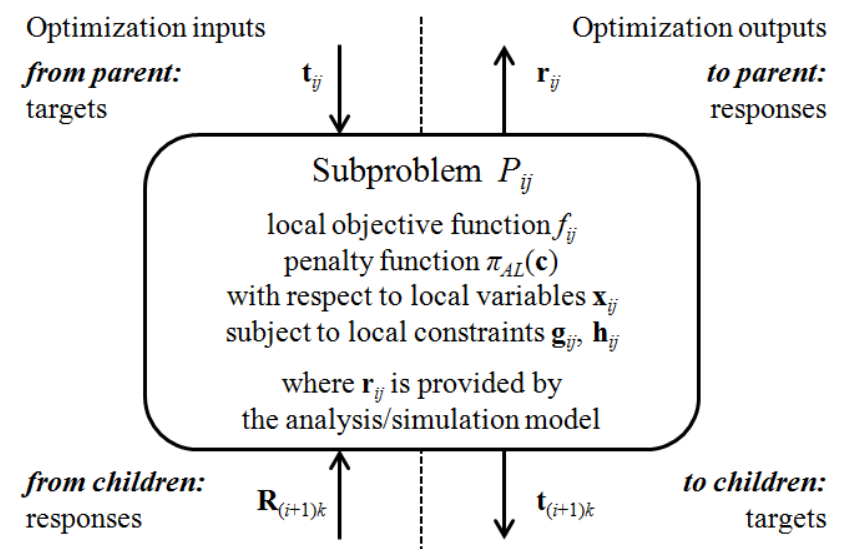

Figure 1. Information flow for ATC subproblem (adopted from Refs. 7 and 8)

with respect to

$$
\min _{\overline{\mathbf{x}}_{i j}} f_{i j}\left(\overline{\mathbf{x}}_{i j}\right)+\pi_{A L}(\mathbf{c})
$$

subject to

$$
\overline{\mathbf{x}}_{i j}=\left[\mathbf{x}_{i j}, \mathbf{r}_{i j}, \mathbf{t}_{(i+1) k_{1}}, \ldots, \mathbf{t}_{(i+1) k_{c_{i j}}}\right]
$$

$$
\begin{aligned}
& \mathbf{g}_{i j}\left(\overline{\mathbf{x}}_{i j}\right) \leq \mathbf{0} \\
& \mathbf{h}_{i j}\left(\overline{\mathbf{x}}_{i j}\right)=\mathbf{0}
\end{aligned}
$$

where

$$
\begin{aligned}
& \mathbf{r}_{i j}=\mathbf{a}_{i j}\left(\mathbf{x}_{i j}, \mathbf{t}_{(i+1) k_{1}}, \ldots, \mathbf{t}_{(i+1) k_{c_{i j}}}\right) \\
& \pi_{A L}(\mathbf{c})=\mathbf{v}^{\mathrm{T}} \mathbf{c}+\|\mathbf{w} \circ \mathbf{c}\|_{2}^{2} \\
& \mathbf{c}=\left[\mathbf{t}_{i j_{1}}-\mathbf{r}_{i j}, \mathbf{t}_{(i+1) k_{1}}-\mathbf{r}_{(i+1) k_{1}}, \ldots, \mathbf{t}_{(i+1) k_{c_{i j}}}-\mathbf{r}_{(i+1) k_{c_{i j}}}\right]
\end{aligned}
$$

\section{Heavy-duty truck suspension design}

\section{A. Problem formulation}

The suspension system of heavy-duty trucks influences the static and dynamic loading applied to the road by the tires of the vehicle. This loading can cause significant damage to roads and bridges ${ }^{9}$. For this reason, the Korean government regulates the axle load of heavy-duty trucks by requiring it to be less than $10,000 \mathrm{~kg}$. In this study, the suspension of Hyundai's $8 \times 425.5 \mathrm{~T}$ dump truck is designed to conform to this axle-load regulation. The objective is to find optimal suspension characteristics (e.g., stiffness) for the 3 suspensions of the vehicle so that the axle load is as close as possible to $10,000 \mathrm{~kg}$ for each of the 4 vehicle axles.

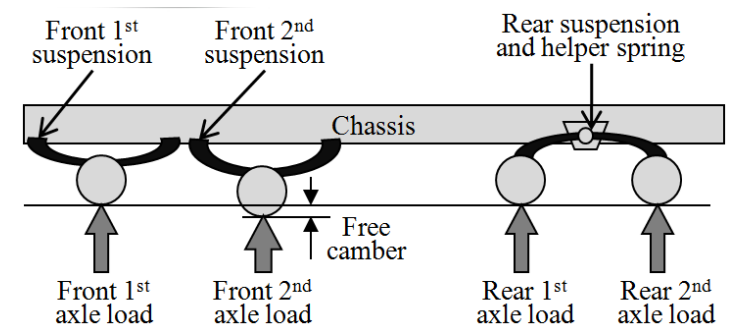

Figure 2. Schematic of current suspension system of Hyundai's $8 \times 4$ heavy-duty dump truck

According to the existing design of an 8x4 25.5T dump truck in Fig. 2, each of the two front suspensions support one of the front two axles. The two rear axles share one suspension system. The overall ATC framework for the axle-load problem is shown on Fig. 3.

American Institute of Aeronautics and Astronautics 


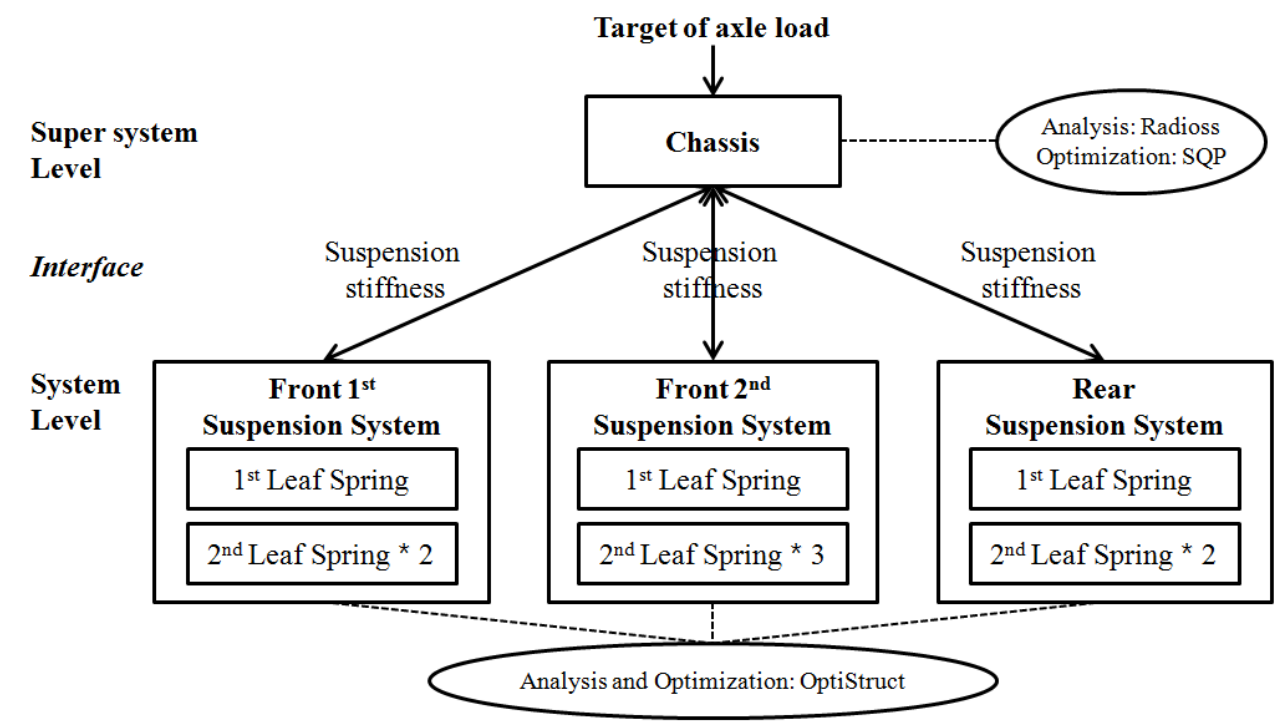

Figure 3. Decomposition and information flow of the ATC process for the axle-load problem.

Table 1. Responses, variables and parameters for axle-load problem

\begin{tabular}{|c|c|}
\hline Level & Variables and parameters \\
\hline $\begin{array}{c}\text { Super } \\
\text { system } \\
\text { level }\end{array}$ & $\begin{array}{l}\text { Response } \\
R F_{1}: \text { Front } 1 \text { st axle load } \\
R F_{2}: \text { Front } 2 \text { nd axle load } \\
R F_{3}: \text { Rear } 1 \text { st axle load } \\
R F_{4}: \text { Rear 2nd axle load } \\
\text { Local design variables } \\
K_{h}: \text { Helper spring stiffness } \\
D_{h}: \text { Gap between chassis and helper spring } \\
C B: \text { Relative free camber of front } 2 \text { nd suspension } \\
\text { Parameter } \\
K_{f t}: \text { Front tire stiffness } \\
K_{r t}: \text { Rear tire stiffness }\end{array}$ \\
\hline Interface & $\begin{array}{l}\text { Linking variables between super system level and system level } \\
K_{f 1}: \text { Front } 1 \text { st suspension stiffness } \\
K_{f 2}: \text { Front } 2 \text { nd suspension stiffness } \\
K_{r}: \text { Rear suspension stiffness w/o helper spring }\end{array}$ \\
\hline $\begin{array}{c}\text { System } \\
\text { level }\end{array}$ & $\begin{array}{l}\text { Local design variables } \\
A_{f 1 j} B_{f 1 j} C_{f 1 j} D_{f 1 j} L_{3 f 1 j} L_{6 f 1 j}: \text { Dimensions of } \mathrm{j} \text {-th leaf spring in front } 1 \text { st suspension }(\mathrm{j}=1,2) \\
A_{f 2 j} B_{f 2 j} C_{f 2 j} D_{f 2 j} L_{3 f 2 j} L_{6 f 2 j} \text { : Dimensions of } \mathrm{j} \text {-th leaf spring in front } 2 \text { nd suspension }(\mathrm{j}=1,2) \\
A_{r j} B_{r j} C_{r j} D_{r j} L_{3 r j} L_{6 r j}: \text { Dimensions of } \mathrm{j} \text {-th leaf spring in front } 1 \text { st suspension }(\mathrm{j}=1,2) \\
\text { Parameter } \\
L_{1} L_{2} L_{4} L_{5}: \text { Fixed dimensions of leaf spring }\end{array}$ \\
\hline
\end{tabular}

The ATC decomposition for the axle-load problem consists of two levels: the super-system level represents the truck's chassis and the system level includes the suspension systems. The first front and rear suspensions consist of three leaf springs. The second front suspension consists of four leaf springs. Note that for all suspensions, the design of the first, large leaf spring generally differs from that of the other leaf springs, which are all identical. At the chassis level, Radioss (an Altair Engineering software product) is used for analysis and Matlab's implementation of the Sequential Quadratic Programming (SQP) algorithm (the 'fmincon' matlab function) is used for optimization. At 
the suspension level, OptiStruct (an Altair Engineering software product) is used for both analysis and optimization, which is a unique implementation feature of the ATC process. The pairs of design targets and responses, design variables and parameters are listed in Table 1.

The objective of the super-system level is to find optimal stiffness values for the suspensions so that axle load is as close as possible to $10,000 \mathrm{~kg}$ for each of the 4 vehicle axles. The super-system design problem is stated in Eq. (2). The lower and upper bounds of each design variable were determined based on currently used $8 \times 425.5 \mathrm{~T}$ dump truck design parameters. Super-system responses $\left(R F_{\mathrm{i}}\right)$ and local variables are obtained using the Radioss simulation model. A tolerance constraint for exceeding each $R F_{\mathrm{i}}$ is included according to regulation tightness. Superscripts $(\cdot)^{\mathrm{U}}$ and $(\cdot)^{\mathrm{L}}$ indicate variables from upper level and from lower level, respectively.

with respect to

$$
\min _{\overline{\mathbf{x}}}\|\mathbf{R F}-\mathbf{1 0 0 0 0}\|_{2}^{2}+\pi_{A L}(\mathbf{c})
$$

$$
\overline{\mathbf{x}}=\left[K_{f 1}^{U}, K_{f 2}^{U}, K_{r}^{U}, C B, D_{h}, K_{h}\right]
$$

subject to

$$
\begin{aligned}
& l b \leq \mathbf{x} \leq u b \\
& R F_{i}-10000 \leq \varepsilon
\end{aligned}
$$

where

$$
\begin{aligned}
& R F_{i}=\mathbf{f}\left(\mathbf{x}, K_{f t}, K_{r t}\right), i=1,2,3,4 \\
& \mathbf{c}=\left[K_{f 1}^{U}-K_{f 1}^{L}, K_{f 2}^{U}-K_{f 2}^{L}, K_{r}^{U}-K_{r}^{L}\right]
\end{aligned}
$$

To satisfy the target values obtained at the super-system level, the design problem for each suspension $i$, where $i$ $\in\{\mathrm{f} 1, \mathrm{f} 2, \mathrm{r}\}$, is given by

with respect to

$$
\min _{\mathbf{x}} \pi_{A L}(\mathbf{c})
$$

subject to

$$
\mathbf{x}=\left[A_{i j}, B_{i j}, C_{i j}, D_{i j}, L_{3 i j}, L_{6 i j}\right], j=1,2
$$

$$
l b \leq \mathbf{x} \leq u b
$$

where

$$
\begin{aligned}
& K_{i}^{L}=\mathbf{f}\left(\mathbf{x}, L_{1}, L_{2}, L_{4}, L_{5}\right) \\
& \mathbf{c}=\left[K_{i}^{U}-K_{i}^{L}\right]
\end{aligned}
$$

The local design variables at the system level are obtained using the OptiStruct simulation and optimization model shown in Fig. 4. Colors are used to denote the degree of shape change from initial value: red indicates largest degree of change and blue indicates lowest degree of change.

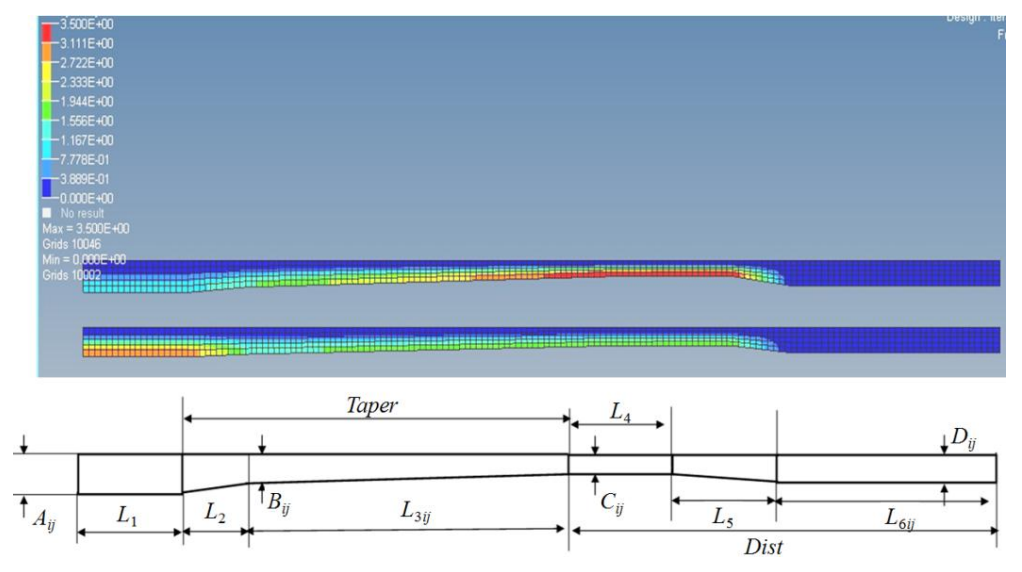

Figure 4. OptiStruct model of suspension system and design variables and parameters 


\section{B. Results}

The ATC process converged after 2 iterations. The obtained target values for the responses are listed in Table 2. The obtained results are acceptable since axle load is very close to $10,000 \mathrm{~kg}$ for each of the 4 vehicle axles; moreover there is overall improvement relative to the HMC baseline values. Table 3 summarizes the pairs of target and response values at the system level. In terms of local design variables computed at the super system level, Table 4 shows that the optimal value of relative free camber of front 2 nd suspension is quite different from the baseline HMC value. This is because it has the highest sensitivity among design variables at the super system, and it contributes most of improvement of response in Table 2. Table 5 lists the optimal local design optimization variable values for each suspension system. The optimization variables were scaling variables that denote deviation from the initial leaf spring dimensions. Superscripts $(\cdot)^{\mathrm{lb}}$ and $(\cdot)^{\mathrm{ub}}$ indicate variables at their lower and upper bounds, respectively. Three dimensions of the front $2^{\text {nd }}$ suspension are hitting lower bounds, which indicates that the design space may be over-restricted and that a parametric study with respect to these variable bounds is recommended.

Table 2. Baseline and final values for target at the super-system level

\begin{tabular}{lcccc}
\hline \multicolumn{1}{c}{ Response } & Target value & Baseline value & Final value & Improvement \\
\hline Front $1^{\text {st }}$ axle load $[\mathrm{kg}]$ & 10,000 & 10,549 & 10,215 & $3.34 \%$ \\
Front $2^{\text {nd }}$ axle load $[\mathrm{kg}]$ & 10,000 & 9,578 & 10,105 & $3.17 \%$ \\
Rear $1^{\text {st }}$ axle load $[\mathrm{kg}]$ & 10,000 & 9,956 & 9,861 & $-0.95 \%$ \\
Rear $2^{\text {nd }}$ axle load $[\mathrm{kg}]$ & 10,000 & 9,956 & 9,861 & $-0.95 \%$ \\
\hline
\end{tabular}

Table 3. Baseline, target and response values for linking variables between super-system and system levels

\begin{tabular}{lcccc}
\hline \multicolumn{1}{c}{ Variable } & $\begin{array}{c}\text { Baseline } \\
\text { value }\end{array}$ & $\begin{array}{c}\text { Target value } \\
\text { from super } \\
\text { system level }\end{array}$ & $\begin{array}{c}\text { Response value } \\
\text { from system } \\
\text { level }\end{array}$ & $\begin{array}{c}\text { Deviation } \\
\text { between target } \\
\text { and response }\end{array}$ \\
\hline Front $1^{\text {st }}$ suspension stiffness $[\mathrm{N} / \mathrm{mm}]$ & 550 & 550 & 549 & $-0.2 \%$ \\
Front $2^{\text {nd }}$ suspension stiffness $[\mathrm{N} / \mathrm{mm}]$ & 550 & 554 & 551 & $-0.5 \%$ \\
Rear suspension stiffness $[\mathrm{N} / \mathrm{mm}]$ & 2,300 & 2,282 & 2,307 & $1.1 \%$ \\
\hline
\end{tabular}

Table 4. Baseline and final values for local design variables computed at the super-system level

\begin{tabular}{lcc}
\hline \multicolumn{1}{c}{ Variable } & Baseline value & Final value \\
\hline Gap between chassis and helper spring $[\mathrm{mm}]$ & 17.50 & 18.53 \\
Relative free camber of front 2nd suspension [mm] & 0.00 & 7.19 \\
Helper spring stiffness [N/mm] & 1,350 & 1,350 \\
\hline
\end{tabular}

Table 5. Baseline and final values for local design variables computed at the system level

Final value

\begin{tabular}{lcccccc} 
Variable & \multicolumn{2}{c}{ Front $1^{\text {st }}$ suspension } & \multicolumn{2}{c}{ Front $2^{\text {nd }}$ suspension } & \multicolumn{2}{c}{ Rear suspension } \\
& $1^{\text {st }}$ spring & $2^{\text {nd }}$ spring & $1^{\text {st }}$ spring & $2^{\text {nd }}$ spring & $1^{\text {st }}$ spring & $2^{\text {nd }}$ spring \\
\hline Dimension A & $-7.70 \mathrm{E}-01$ & $-7.72 \mathrm{E}-01$ & $-1.00 \mathrm{E}+00$ & $-3.00 \mathrm{E}+00^{\mathrm{lb}}$ & $1.26 \mathrm{E}+01$ & $1.26 \mathrm{E}+01$ \\
Dimension B & $-1.84 \mathrm{E}-01$ & $-2.59 \mathrm{E}-01$ & $-1.50 \mathrm{E}+00$ & $-1.50 \mathrm{E}+00^{\text {lb }}$ & $1.25 \mathrm{E}+01$ & $6.56 \mathrm{E}+00$ \\
Dimension C & $-1.43 \mathrm{E}-01$ & $-2.00 \mathrm{E}-01$ & $-3.50 \mathrm{E}+00^{\mathrm{lb}}$ & $-1.78 \mathrm{E}+00$ & $1.23 \mathrm{E}+01$ & $1.42 \mathrm{E}+01$ \\
Dimension D & $-1.58 \mathrm{E}+00$ & $-1.35 \mathrm{E}+00$ & $-2.83 \mathrm{E}-04$ & $-1.68 \mathrm{E}-01$ & $6.74 \mathrm{E}+00$ & $9.99 \mathrm{E}+00$ \\
Dimension $\mathrm{L}_{3}$ & $-1.60 \mathrm{E}-05$ & $-3.05 \mathrm{E}-05$ & $-5.59 \mathrm{E}-05$ & $-2.02 \mathrm{E}-04$ & $2.76 \mathrm{E}+01$ & $-4.17 \mathrm{E}+01$ \\
\hline
\end{tabular}




\section{Bus body structure design}

\section{A. Problem formulation}

Determining stiffness and mass design specifications for each body assembly is a challenging task for bus body structure system designers. The objectives of the bus body structure design study include investigating design variable interactions among the beams of the body structure to ensure robust assembly and optimizing beam cross section geometry to satisfy bus body structure design targets related to structural stiffness. The ATC framework and the detailed nomenclature for the bus problem are given in Fig. 5 and Table 6, respectively. The ATC decomposition of the bus problem consists of three levels.

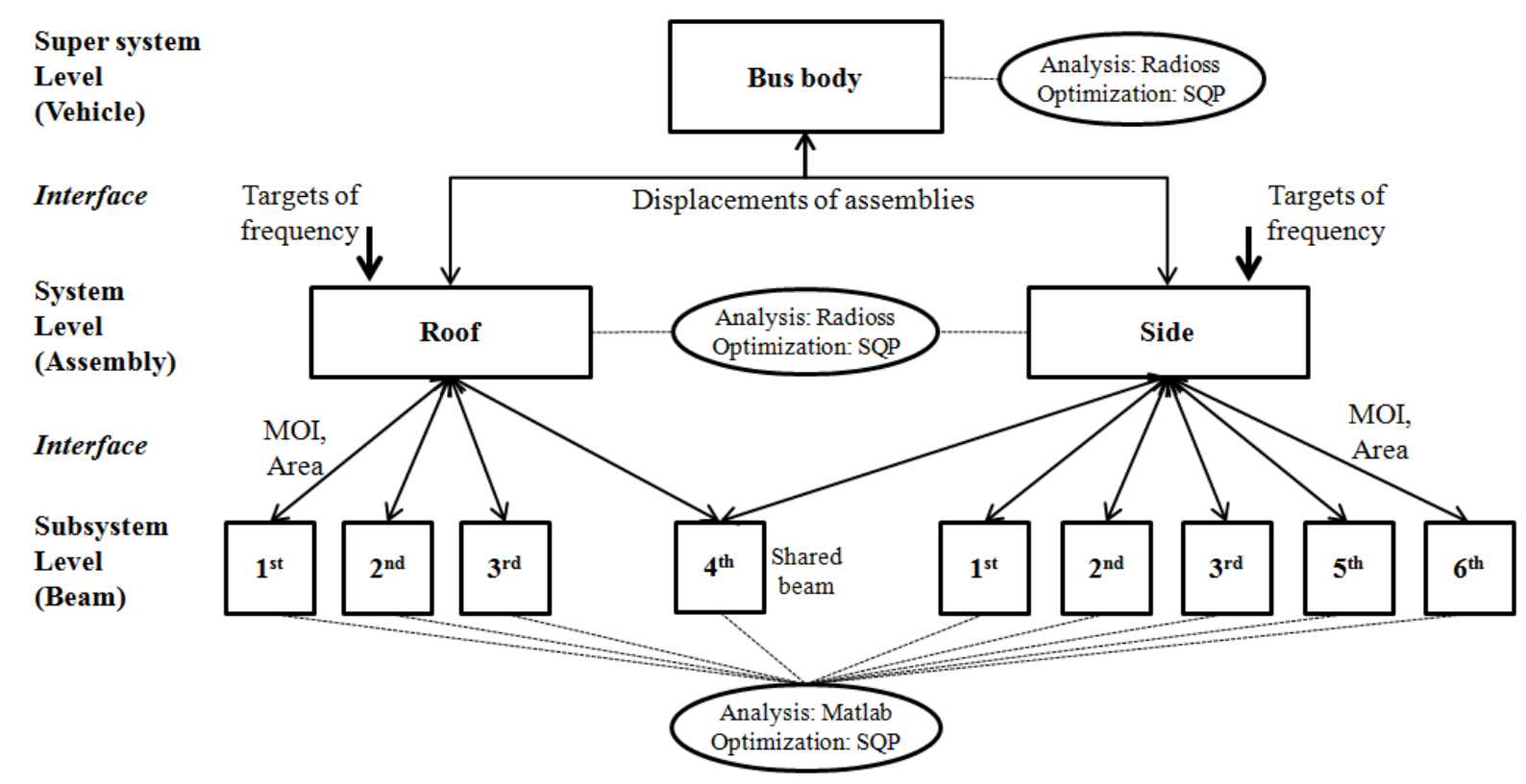

Figure 5. Decomposition and information flow of the ATC process for the bus body structure problem.

The super-system level represents the whole bus body structure, which consists of five assemblies (roof, side, front, rear, and floor) modeled with beam elements. Displacements of assemblies, which represent static stiffness, are used for linking variables between super system level and system level. The system level considers two assembly systems, roof and side, which are the most important part in terms of stiffness of bus body structure. The system level has local targets of frequency which represent dynamic stiffness. Moments of inertia (MOI) and area of beam cross section are used to link the system level and subsystem level. Lastly, the subsystem level includes the beam cross-section models. Roof assembly has four beams, and side assembly has six beams. Especially the fourth beam of each system is the same component sharing in two assemblies. Therefore, the fourth beam gets two targets from roof and side, and then gives back the one response to the two systems. At the super system and system level, Radioss is used for analysis and Matlab's implementation of the SQP algorithm is used for optimization. At the subsystem level, Matlab itself is used for analysis and the SQP algorithm is used for optimization.

The objective of the super-system problem is to minimize total body mass and deviation of linking variables between super-system and system level. As linking variables, each displacement of roof and side assemblies have two values according to bending and twisting mode. Local design variables are proportional factors of material property of five assemblies, which change the modulus of elasticity and density of body material (i.e., optimal modulus of elasticity of material $=$ optimal $a *$ initial modulus of elasticity; optimal density of material = optimal $a *$ initial density). The initial material properties are set as steel. Proportional factors of material property have the lower and upper bounds, and frequencies of $1^{\text {st }}$ and $2^{\text {nd }}$ mode have the only lower bound. Every response is obtained using the Radioss simulation model. The design problem is formulated as Eq. (4). 
Table 6. Targets, responses, variables and parameters for bus body structure problem

\begin{tabular}{|c|c|}
\hline Level & Variables and parameter \\
\hline $\begin{array}{c}\text { Super } \\
\text { system } \\
\text { level }\end{array}$ & $\begin{array}{l}\text { Response } \\
m: \text { Total mass } \\
f_{i}: \text { Frequency of vehicle of } i \text {-th mode }\left(i=1,2: 1^{\text {st }} \text { mode, } 2: 2^{\text {nd }} \text { mode }\right) \\
\text { Local design variables } \\
\left.a_{i}: \text { Proportional factor of material property of } i \text {-th assembly ( } i=1: \text { roof, } 2: \text { side, } 3: \text { front, } 4: \text { rear, } 5: \text { floor }\right) \\
\text { Parameter } \\
E_{0}: \text { Initial modulus of elasticity of steel } \\
\rho_{0}: \text { Initial density of steel }\end{array}$ \\
\hline Interface & $\begin{array}{l}\text { Linking variables between super system level and system level } \\
d_{i j}: \text { Displacement for } i \text {-th assembly and } j \text {-th condition ( } i=1 \text { : roof, } 2 \text { : side; } j=1 \text { : bending, } 2 \text { : twisting) }\end{array}$ \\
\hline $\begin{array}{c}\text { System } \\
\text { level }\end{array}$ & $\begin{array}{l}\text { Local target } \\
f_{t-i j}: \text { Target of frequency for } i \text {-th assembly and } j \text {-th mode }\left(i=1: \text { roof, } 2: \text { side; } j=1: 1^{\text {st }} \text { mode, } 2: 2^{\text {nd }} \text { mode }\right) \\
\text { Response } \\
m_{i}: \text { Mass of } i \text {-th assembly }(i=1: \text { roof, } 2: \text { side }) \\
\left.f_{i j}: \text { Frequency for } i \text {-th assembly and } j \text {-th mode ( } i=1: \text { roof, } 2: \text { side; } j=1: 1^{\text {st }} \text { mode, } 2: 2^{\text {nd }} \text { mode }\right)\end{array}$ \\
\hline Interface & $\begin{array}{l}\text { Linking variables between system level and subsystem level } \\
I_{1_{i j} j}: \text { MOI in plane } 1 \text { for } i \text {-th assembly and } j \text {-th beam }(i=1: \text { roof; } j=1,2,3,4)(i=2 \text { : side; } j=1,2,3,4,5,6) \\
I_{2_{i j}}: \text { MOI in plane } 2 \text { for } i \text {-th assembly and } j \text {-th beam }(i=1 \text { : roof; } j=1,2,3,4)(i=2 \text { : side; } j=1,2,3,4,5,6) \\
A_{i j}: \text { Area of cross section for } i \text {-th assembly and } j \text {-th beam }(i=1 \text { : roof; } j=1,2,3,4)(i=2: \text { side; } j=1,2,3,4,5,6)\end{array}$ \\
\hline $\begin{array}{l}\text { Sub } \\
\text { system } \\
\text { level }\end{array}$ & $\begin{array}{l}\text { Local design variable } \\
w_{i j}: \text { Width of cross section for } i \text {-th assembly and } j \text {-th beam }(i=1 \text { : roof; } j=1,2,3,4)(i=2: \text { side; } j=1,2,3,4,5,6) \\
h_{i j}: \text { Height of cross section for } i \text {-th assembly and } j \text {-th beam }(i=1: \text { roof; } j=1,2,3,4)(i=2: \text { side; } j=1,2,3,4,5,6) \\
t_{i j}: \text { Thickness of cross section for } i \text {-th assembly and } j \text {-th beam }(i=1 \text { : roof; } j=1,2,3,4)(i=2: \text { side; } j=1,2,3,4,5,6)\end{array}$ \\
\hline \multicolumn{2}{|c|}{ 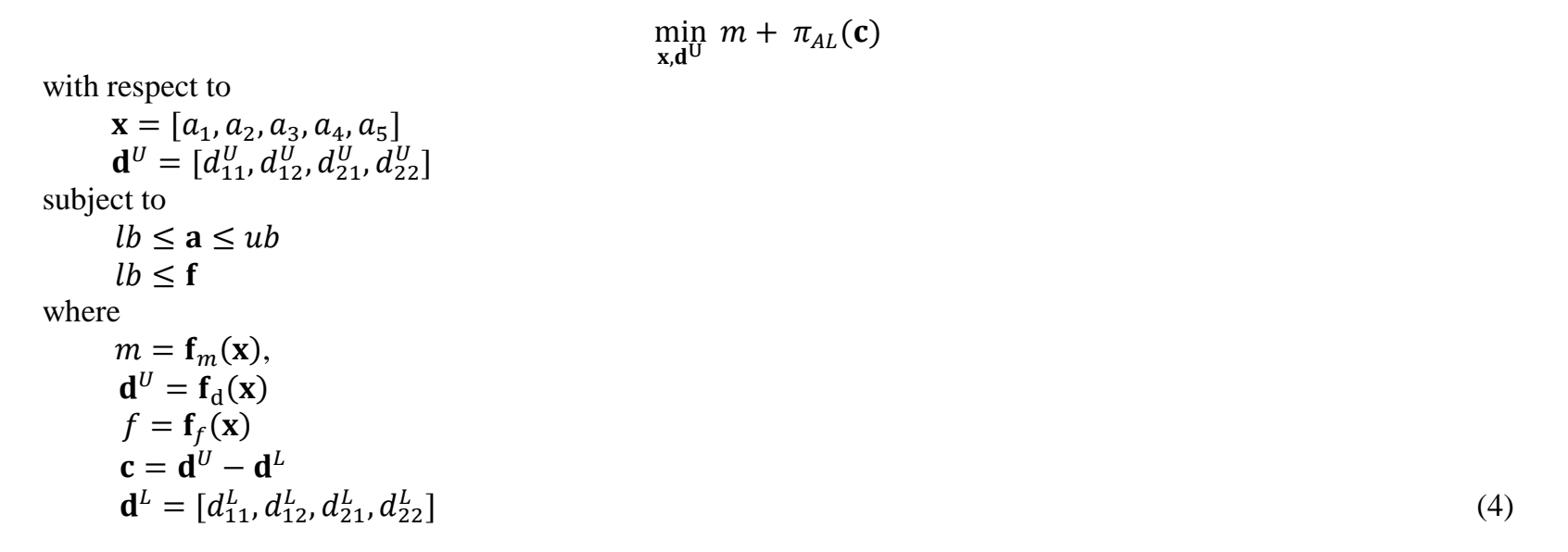 } \\
\hline
\end{tabular}

The system level consists of roof assembly and side assembly. The objective is to minimize the mass, deviation of linking variables with upper and lower levels, and to satisfy the local targets of frequency of $1^{\text {st }}$ and $2^{\text {nd }}$ mode. The system level does not have local design variables. For linking variables with subsystem level, MOI and area of beam cross section have the lower and upper bound. Every response for target from super system level is obtained using the Radioss simulation model. This Radioss model of roof and side for calculating the static and dynamic stiffness are illustrated in Fig. 6. For example, the design problem of roof system is formulated as Eq. (5). 

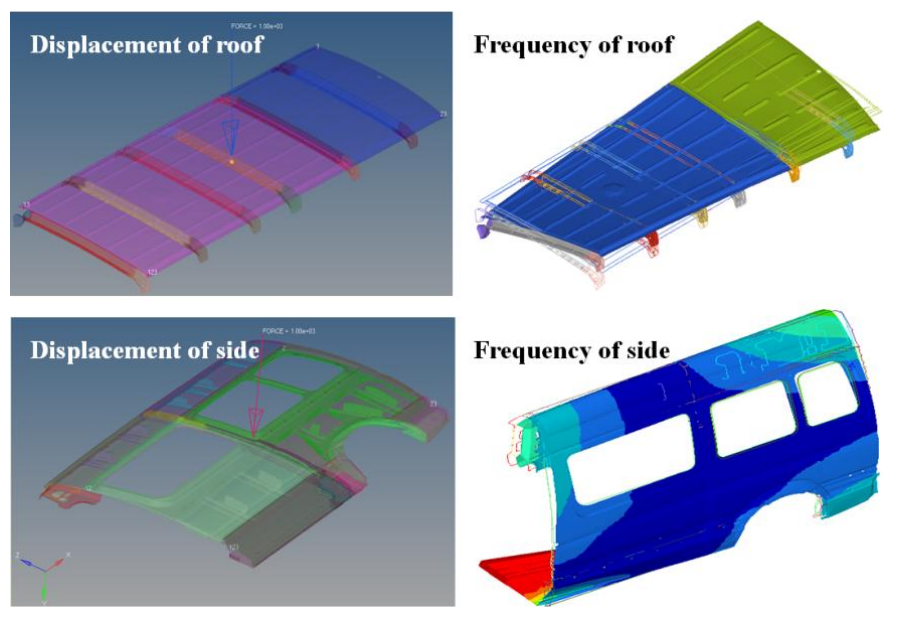

Figure 6. Radioss model for analysis at the system level

with respect to

$$
\min _{\mathbf{I}_{1}^{\mathrm{U}}, \mathbf{I}_{2_{-}}^{\mathrm{U}}, \mathbf{A}_{1}^{\mathrm{U}}} m_{1}+\left\|\mathbf{f}_{t_{-} 1}-\mathbf{f}_{1}\right\|_{2}^{2}+\pi_{A L}(\mathbf{c})
$$

$$
\begin{aligned}
& \mathbf{I}_{1 \_1}^{U}=\left[I_{1 \_11}^{U}, I_{1 \_12}^{U}, I_{1 \_13}^{U}, I_{1 \_14}^{U}\right] \\
& \mathbf{I}_{2 \_1}^{\mathrm{U}}=\left[I_{2 \_11}^{U}, I_{2 \_12}^{U}, I_{2 \_13}^{U}, I_{2 \_}^{U} 14\right] \\
& \mathbf{A}_{1}^{\mathrm{U}}=\left[A_{11}^{U}, A_{12}^{U}, A_{13}^{U}, A_{14}^{U}\right]
\end{aligned}
$$

subject to

$$
\begin{aligned}
& l b \leq \mathbf{I}_{1}^{\mathrm{U}} \leq u b \\
& l b \leq \mathbf{I}_{2}^{\mathrm{U}} \leq u b \\
& l b \leq \mathbf{A}_{1}^{\bar{U}} \leq u b
\end{aligned}
$$

where

$$
\begin{aligned}
& m_{1}=\mathbf{f}_{m}\left(\mathbf{I}_{1 \_1}^{\mathrm{U}}, \mathbf{I}_{2 \_}^{\mathrm{U}}, \mathbf{A}_{1}^{\mathrm{U}}\right) \\
& \mathbf{f}_{1}=\mathbf{f}_{f}\left(\mathbf{I}_{1_{\_}}^{\mathrm{U}}, \mathbf{I}_{2_{\_}}^{\mathrm{U}}, \mathbf{A}_{1}^{\mathrm{U}}\right) \\
& \mathbf{f}_{1}=\left[f_{11}, f_{12}\right] \\
& \mathbf{c}=\left[\mathbf{d}_{1}^{U}-\mathbf{d}_{1}^{L}, \mathbf{I}_{1 \_1}^{\mathrm{U}}-\mathbf{I}_{1 \_1}^{\mathrm{L}}, \mathbf{I}_{2_{-} 1}^{\mathrm{U}}-\mathbf{I}_{2 \_1}^{\mathrm{L}}, \mathbf{A}_{1}^{\mathrm{U}}-\mathbf{A}_{1}^{\mathrm{L}}\right] \\
& \mathbf{d}_{1}^{L}=\mathbf{f}\left(\mathbf{I}_{1_{-}}^{\mathrm{U}}, \mathbf{I}_{2-1}^{\mathrm{U}}, \mathbf{A}_{1}^{\mathrm{U}}\right) \\
& \mathbf{d}_{1}^{L}=\left[d_{11}^{L}, d_{12}^{L}\right] \\
& \mathbf{I}_{1 \_1}^{\mathrm{L}}=\left[I_{1 \_11}^{L}, I_{1 \_12}^{L}, I_{1 \_13}^{L}, I_{1 \_14}^{L}\right] \\
& \mathbf{I}_{2 \_1}^{\mathrm{L}}=\left[I_{2 \_11}^{L}, I_{2 \_12}^{L}, I_{2 \_13}^{L}, I_{2 \_14}^{L}\right] \\
& \mathbf{A}_{1}^{\mathrm{L}}=\left[A_{11}^{L}, A_{12}^{L}, A_{13}^{L}, A_{14}^{L}\right]
\end{aligned}
$$

$\min _{\mathbf{x}} \pi_{A L}(\mathbf{c})$

with respect to

subject to

$$
\mathbf{x}=\left[w_{14}, h_{14}, t_{14}\right]
$$

$l b \leq w_{14} \leq u b$
$l b \leq h_{14} \leq u b$

$l b \leq t_{14} \leq u b$

where

$$
\begin{aligned}
& \mathbf{c}=\left[I_{1_{-} 14}^{U}-I_{1_{-} 14}^{L}, I_{2_{-} 14}^{U}-I_{2_{-} 14}^{L}, A_{14}^{U}-A_{14}^{L}, I_{2_{-} 24}^{U}-I_{1_{-} 14}^{L}, I_{1_{-} 24}^{U}-I_{2_{-} 14}^{L}, A_{24}^{U}-A_{14}^{L}\right] \\
& I_{1}^{L} \mathbf{f}_{I_{1}}\left(w_{14}, h_{14}, t_{14}\right) \\
& I_{2_{14}}^{L}=\mathbf{f}_{I_{2}}\left(w_{14}, h_{14}, t_{14}\right) \\
& A_{14}^{L}=\mathbf{f}_{A}\left(w_{14}, h_{14}\right)
\end{aligned}
$$


To satisfy the target value from system level, the design problem for the fourth beam of roof at the subsystem level is given by Eq. (6). As it is mentioned before, this beam is the shared component so that deviations of linking variables are related with two parents: roof assembly (i.e., $\left[I_{1_{14}}^{U}-I_{1_{14}}^{L}, I_{2_{14}}^{U}-I_{2_{14}}^{L}, A_{14}^{U}-A_{14}^{L}, I_{2_{24}}^{U}-I_{1_{14}}^{L}\right]$ ) and side assembly (i.e., $\left[I_{2 \_24}^{U}-I_{1 \_14}^{L}, I_{1 \_24}^{U}-I_{2 \_14}^{L}, A_{24}^{U}-A_{14}^{L}\right]$ ). Since this subsystem has two parents, we use the nonhierarchical ATC formulation of Ref. 8. The roof and side models have opposite axis so that $I_{1}$ for roof and $I_{2}$ for side make a pair.

\section{B. Results}

The ATC process converged after 5 iterations. The target values for the responses computed at the super-system level and system level are presented in Table 7. In terms of total mass of body, a significant improvement of $21.1 \%$ over the HMC baseline value has been achieved. For frequency of roof and side, there is a balanced improvement relative to HMC baseline values. Even though these final frequency values tend to be little larger than the set local design targets, the mismatch is not large enough to affect other component frequencies adversely. In addition, according to HMC engineers, the set local target values for the frequenices must be reviewed as the simulation models have been modified since they were first determined.

Table 7. Baseline and final values for target at the super system and system level

\begin{tabular}{cccccc}
\hline Level & Response & Target value & Baseline value & Final value & Improvement \\
\hline $\begin{array}{c}\text { Super } \\
\text { system }\end{array}$ & Total mass, $m$ [ton] & 0 & 0.5803 & 0.4578 & $21.1 \%$ \\
\hline \multirow{5}{*}{ System } & Mass of roof, $m_{1}[$ ton] & 0 & 0.0416 & 0.0481 & $-15.6 \%$ \\
& Mass of side, $m_{2}[\mathrm{ton}]$ & 0 & 0.0871 & 0.0813 & $6.7 \%$ \\
& $1^{\text {st }}$ mode frequency of roof, $f_{11}[\mathrm{~Hz}]$ & 5.825 & 5.236 & 4.971 & $-4.6 \%$ \\
& $2^{\text {nd }}$ mode frequency of roof, $f_{12}[\mathrm{~Hz}]$ & 8.650 & 9.052 & 8.390 & $1.6 \%$ \\
& $1^{\text {st }}$ mode frequency of side, $f_{11}[\mathrm{~Hz}]$ & 5.676 & 10.008 & 9.797 & $3.7 \%$ \\
& $2^{\text {nd }}$ mode frequency of side, $f_{12}[\mathrm{~Hz}]$ & 7.785 & 12.879 & 12.900 & $-0.3 \%$ \\
\hline
\end{tabular}

The response values at the system level listed in Table 8 satisfy the targets from the super-system level within approximately $10 \%$. This can be considered as reasonable given existing design constraints.

Table 8. Baseline, target, and response values for linking variables between super system and system level

\begin{tabular}{|c|c|c|c|c|}
\hline Variable & Baseline value & $\begin{array}{c}\text { Target value } \\
\text { from super } \\
\text { system level } \\
\end{array}$ & $\begin{array}{c}\text { Response value } \\
\text { from system } \\
\text { level }\end{array}$ & $\begin{array}{c}\text { Deviation } \\
\text { between target } \\
\text { and response }\end{array}$ \\
\hline $\begin{array}{c}\text { Displacement of roof } \\
\text { at bending mode, } d_{11}[\mathrm{~mm}]\end{array}$ & 72.6 & 66.9 & 67.4 & $-0.8 \%$ \\
\hline $\begin{array}{l}\text { Displacement of roof } \\
\text { at twisting mode, } d_{12}[\mathrm{~mm}]\end{array}$ & 490.0 & 451.4 & 447.3 & $0.9 \%$ \\
\hline $\begin{array}{l}\text { Displacement of side } \\
\text { at bending mode, } d_{21}[\mathrm{~mm}]\end{array}$ & 17.5 & 16.9 & 18.7 & $-10.3 \%$ \\
\hline $\begin{array}{l}\text { Displacement of side } \\
\text { at twisting mode, } d_{22}[\mathrm{~mm}]\end{array}$ & 84.7 & 82.0 & 72.5 & $11.6 \%$ \\
\hline
\end{tabular}

Table 9 lists response valuess at the subsystem level; they satisfy the targets from the system level reasonably well except for four variables in the $2^{\text {nd }}, 3^{\text {rd }}$ and $4^{\text {th }}$ side beam cross sections. This issue is directly traceable to the local design variable results at the subsystem level listed in Table 10. Many optimal values are hitting the lower or upper bounds. It is evident that the considered beam configurations and/or design space need to be revisited. 
Table 9. Baseline, target, and response values for linking variables between system and sub system level

\begin{tabular}{|c|c|c|c|c|c|c|}
\hline Assembly & Beam & Variable & $\begin{array}{c}\text { Baseline } \\
\text { value }\end{array}$ & $\begin{array}{c}\text { Target } \\
\text { value from } \\
\text { system } \\
\text { level }\end{array}$ & $\begin{array}{c}\text { Response } \\
\text { value from } \\
\text { subsystem } \\
\text { level }\end{array}$ & $\begin{array}{c}\text { Deviation } \\
\text { between } \\
\text { target and } \\
\text { response }\end{array}$ \\
\hline \multirow{12}{*}{ Roof } & \multirow{3}{*}{$1^{\mathrm{st}}$} & Area of cross section, $A_{11}\left[\mathrm{~mm}^{2}\right]$ & 145 & 255 & 253 & $1.0 \%$ \\
\hline & & MOI in plane $1, I_{1 \_11}\left[\mathrm{~mm}^{4}\right]$ & 132,770 & 132,770 & 122,980 & $7.0 \%$ \\
\hline & & MOI in plane 2, $I_{2 \_11}\left[\mathrm{~mm}^{4}\right]$ & 47,363 & 47,364 & 48,357 & $-2.0 \%$ \\
\hline & \multirow{3}{*}{$2^{\text {nd }}$} & $A_{12}$ & 145 & 260 & 253 & $3.0 \%$ \\
\hline & & $I_{1 \_12}$ & 132,770 & 132,770 & 123,060 & $7.0 \%$ \\
\hline & & $I_{2 \_12}$ & 47,363 & 47,364 & 48,463 & $-2.0 \%$ \\
\hline & \multirow{3}{*}{$3^{\text {rd }}$} & $A_{13}$ & 182 & 195 & 195 & $0.0 \%$ \\
\hline & & $I_{1 \_13}$ & 169,346 & 169,350 & 169,710 & $0.0 \%$ \\
\hline & & $I_{2 \_13}$ & 59,310 & 59,310 & 59,297 & $0.0 \%$ \\
\hline & \multirow{3}{*}{$4^{\text {th }}$} & $A_{14}$ & 145 & 184 & 183 & $1.0 \%$ \\
\hline & & $I_{1 \_14}$ & 132,770 & 132,770 & 146,560 & $-10.0 \%$ \\
\hline & & $I_{2 \_14}$ & 47,363 & 47,366 & 54,037 & $-14.0 \%$ \\
\hline \multirow{18}{*}{ Side } & \multirow{3}{*}{$1^{\mathrm{st}}$} & $A_{21}$ & 179 & 227 & 228 & $0.0 \%$ \\
\hline & & $I_{1 \_21}$ & 147,847 & 147,850 & 147,760 & $0.0 \%$ \\
\hline & & $I_{2 \_21}$ & 238,231 & 238,230 & 238,070 & $0.0 \%$ \\
\hline & \multirow{3}{*}{$2^{\text {nd }}$} & $A_{22}$ & 293 & 334 & 335 & $0.0 \%$ \\
\hline & & $I_{1 \_22}$ & 148,887 & 148,890 & 155,120 & $-4.0 \%$ \\
\hline & & $I_{2 \_22}$ & $1,355,558$ & $1,355,600$ & 243,040 & $82.0 \%$ \\
\hline & \multirow{3}{*}{$3^{\text {rd }}$} & $A_{23}$ & 264 & 308 & 309 & $0.0 \%$ \\
\hline & & $I_{1 \_23}$ & 137,125 & 137,130 & 142,560 & $-4.0 \%$ \\
\hline & & $I_{2 \_23}$ & $1,085,500$ & $1,085,500$ & 171,560 & $84.0 \%$ \\
\hline & \multirow{3}{*}{$4^{\text {th }}$} & $A_{24}$ & 310 & 183 & 183 & $0.0 \%$ \\
\hline & & $I_{1 \_24}$ & 268,936 & 268,940 & 54,037 & $80.0 \%$ \\
\hline & & $I_{2 \_24}$ & $1,113,880$ & $1,113,900$ & 146,560 & $87.0 \%$ \\
\hline & \multirow{3}{*}{$5^{\text {th }}$} & $A_{25}$ & 148 & 194 & 194 & $0.0 \%$ \\
\hline & & $I_{1 \_25}$ & 35,469 & 35,468 & 35,445 & $0.0 \%$ \\
\hline & & $I_{2 \_25}$ & 196,589 & 196,590 & 196,540 & $0.0 \%$ \\
\hline & \multirow{3}{*}{$6^{\text {th }}$} & $A_{26}$ & 157 & 205 & 205 & $0.0 \%$ \\
\hline & & $I_{1 \_26}$ & 90,793 & 90,793 & 90,760 & $0.0 \%$ \\
\hline & & $I_{2 \_26}$ & 180,519 & 180,520 & 180,610 & $0.0 \%$ \\
\hline
\end{tabular}

Table 10. Baseline and final values for local design variables computed at the super system level

\begin{tabular}{ccc}
\hline Variable & Baseline value & Final value \\
\hline Proportional factor of material property of roof, $a_{1}$ & 1 & 1.086 \\
Proportional factor of material property of side, $a_{2}$ & 1 & 1.033 \\
Proportional factor of material property of front, $a_{3}$ & 1 & 0.500 \\
Proportional factor of material property of rear, $a_{4}$ & 1 & 1.354 \\
Proportional factor of material property of floor, $a_{5}$ & 1 & 0.812 \\
\hline
\end{tabular}

11

American Institute of Aeronautics and Astronautics 
Table 11. Baseline and final values for local design variables computed at the sub system level

\begin{tabular}{ccccc}
\hline Assembly & Beam & Width, $w_{i j}[\mathrm{~mm}]$ & Height, $h_{i j}[\mathrm{~mm}]$ & Tickness, $t_{i j}[\mathrm{~mm}]$ \\
\hline \multirow{4}{*}{ Roof } & $1^{\text {st }}$ & 32.989 & $60^{\mathrm{ub}}$ & $1.4^{\mathrm{ub}}$ \\
& $2^{\text {nd }}$ & 33.021 & $60^{\mathrm{ub}}$ & $1.4^{\mathrm{ub}}$ \\
& $3^{\text {rd }}$ & 40.363 & $80^{\mathrm{ub}}$ & 0.82096 \\
& $4^{\text {th }}$ & 39.855 & 76.324 & $0.8^{\mathrm{lb}}$ \\
\hline \multirow{5}{*}{ Side } & $1^{\text {st }}$ & 83.26 & 60.836 & $0.8^{\mathrm{lb}}$ \\
& $2^{\text {nd }}$ & $70^{\mathrm{ub}}$ & 52.276 & $1.4^{\mathrm{ub}}$ \\
& $3^{\text {rd }}$ & $60^{\mathrm{ub}}$ & 53.194 & $1.4^{\mathrm{ub}}$ \\
& $4^{\text {th }}$ & 39.855 & 76.324 & $0.8^{\mathrm{bb}}$ \\
& $5^{\text {th }}$ & 90.998 & 30.374 & 0.81037 \\
& $6^{\text {th }}$ & 77.919 & 49.642 & 0.81517 \\
\hline
\end{tabular}

Based on the obtained ATC results, system engineers can investigate the attainable optimal values under different constraints, and can obtain information on which subsystem affects system-level objectives, and can gain insight on how subsystems should be modified to satisfy design targets.

\section{Conclusion}

ATC was applied successfully to two HMC commercial vehicle design problems. The obtained results were meaningful and demonstrate the potential of the ATC methodology in industry settings. An implementation novelty was that OptiStruct was used both for analysis and optimization of the subproblems, making the ATC computational process more simple and efficient.

For the suspension design of a heavy-duty truck, the objective was to make the four vehicle axle loads to be as close as possible to $10,000 \mathrm{~kg}$. The final response values obtained using ATC are closer than current HMC design values. The obtained leaf spring design variable values satisfy stiffness targets obtained at the chassis level.

For the body structure design of a middle-sized bus, the objective at the super system level was to minimize total mass: the final response value obtained using ATC is a significant improvement relative to current HMC initial guesses. The ATC results provide useful insights and guidelines on the feasibility of system-level design targets and the adequacy of the subproblem design spaces.

\section{Acknowledgment}

The first three authors are grateful for the financial support of Hyundai Motor Company. Such support does not constitute an endorsement by the sponsor of the opinions expressed in this article.

\section{References}

\footnotetext{
${ }^{1}$ Kim, H. M., "Target cascading in optimal system design,” Ph.D. Dissertation, Mechanical Engineering Dept., University of Michigan, Ann Arbor, MI, 2001.

${ }^{2}$ Kim, H. M., Kokkolaras, M., Louca, L. S., Delagrammatikas, G. J, Michelena, N. F., Filipi, Z. S., Papalambros, P. Y., Stein, J. L., and Assanis, D. N., "Target cascading in vehicle redesign: a class VI truck study," International Journal of Vehicle Design, Vol. 29, No. 3, 2002, pp. 199-225.

${ }^{3}$ Kim, H. M., Michelena, N. F., Papalambros, P. Y., and Jiang, T., "Target cascading in optimal system design," Journal of Mechanical Design, Vol. 125, No. 3, 2003, pp. 474-480.

${ }^{4}$ Kim, H. M., Rideout, D. G., Papalambros, P. Y., and Stein, J. L., “Analytical target cascading in automotive vehicle design,” Journal of Mechanical Design, Vol. 125, 2003, pp. 481-489.

${ }^{5}$ Kokkolaras, M., Louca, L. S., Delagrammatikas, G. J, Michelena, N. F., Filipi, Z. S., Papalambros, P. Y., Stein, J. L., and Assanis, D.N., "Simulation-based optimal design of heavy trucks by model-based decomposition: An extensive analytical target cascading case study," International Journal of Heavy Vehicle Systems, Vol. 11, No. 3-4, 2004, pp. 403-433.

${ }^{6}$ Michelena, N., Park, H., and Papalambros, P. Y., "Convergence Properties of Analytical Target Cascading". AIAA Journal, Vol. 41, No. 5, 2003, pp. 897-905.
}

12

American Institute of Aeronautics and Astronautics 
${ }^{7}$ Tosserams, S., Etman, L. F. P., Papalambros, P. Y., and Rooda, J. E., "An Augmented Lagrangian Relaxation for Analytical Target Cascading using the Alternating Directions Method of Multipliers," Structural and Multidisciplinary Optimization, Vol. 31, No. 3, 2006, pp. 176-189.

${ }^{8}$ Tosserams, S., Kokkolaras, M., Etman, L. F. P., and Rooda, J. E., "A Nonhierarchical Formulation of Analytical Target Cascading," Journal of Mechanical Design, Vol. 132, 2010, pp. 051002-12.

${ }^{9}$ Cole, D. J., "Fundamental Issues in Suspension Design for Heavy Road Vehicles," Vehicle System Dynamics, Vol. 35, No. 4-5, 2001, pp. 319-360. 